\title{
A homossexualidade feminina no campo da saúde: da invisibilidade à violência
}

| 1 Rita de Cássia Valadão, ${ }^{2}$ Romeu Gomes |

Resumo: O artigo tem como objetivo geral analisar os modelos que podem explicar a invisibilidade de lésbicas e mulheres bissexuais na área da assistência integral à saúde da mulher. Ao se discutir a homossexualidade em geral, contribui-se para que sejam desconstruídas visões naturalistas que destituem das pessoas o papel de agentes de sua própria sexualidade, impedindo-as de exercer o direito de viverem orientações sexuais diferentes das heteronormatizadas. Para o referencial teórico, foram utilizados os conceitos habitus e o campo de Pierre Bourdieu. Como método de estudo, empregou-se o desenho de ensaio, baseando-se em dois conjuntos de fontes: artigos publicados na área da saúde sobre o assunto, acessados no portal da Biblioteca Virtual de Saúde (BVS), e documentos governamentais relacionados ao atendimento às demandas de saúde de lésbicas, mulheres bissexuais ou que vivenciam relações homoafetivas e/ou homoeróticas. Concluiuse que lésbicas e mulheres bissexuais não têm apoio por parte dos profissionais de saúde para verbalizar suas orientações sexuais quando buscam assistência. Tal situação escamoteia um atendimento seguro, produzindo exclusão e violência simbólica, apesar dos programas governamentais preconizarem o contrário.

> Palavras-chave: Homossexualidade feminina; invisibilidade; violência; campo da saúde no Brasil.
${ }^{1}$ Assistente Social, mestre em Ciência pelo Instituto Fernandes Figueira /FIOCRUZ. Endereço eletrônico: ritacv@iff.fiocruz.br

${ }^{2}$ Doutor em Saúde Pública (ENSP/FIOCRUZ), livre docente em Psicologia (UFF). Endereço eletrônico: romeu@iff.fiocruz.br
Recebido em: 17/07/2010 Aprovado em: 04/10/2010 


\section{Considerações iniciais}

No campo das políticas de saúde, observam-se alguns avanços que não só asseguram os direitos da homossexualidade, da lesbiandade e da bissexualidade feminina em se expressar no âmbito das relações afetivo-sexuais, como também garantem o atendimento das demandas de saúde advindas das diferentes orientações sexuais.

Esse preceito legal, entretanto, ainda encontra pela frente algumas barreiras. Uma delas é o fato de que a lesbiandade e as homossexualidades, em geral, constituem-se numa temática atravessada por inúmeros preconceitos e discriminaçôes. Pesquisa realizada em 102 municípios brasileiros, com amostra probabilística com 2.363 entrevistados, constatou que $89 \%$ das pessoas entrevistadas foram contra a homossexualidade masculina e $88 \%$, contra a lesbiandade e a bissexualidade de mulheres (ALMEIDA, 2007). Esse resultado pode ilustrar a ideia hegemônica presente no imaginário social, de que a sexualidade deve ser heterossexual, e aceitar o contrário pode significar ir de encontro a algo considerado como 'natural'.

Por outro lado, ainda que nos discursos não sejam percebidas ideias que rechaçam a homossexualidade, neles, às pessoas que não partilham exclusivamente da heteronormatividade costuma-se destinar o status "menos humanas" (FLEURY \& TORRES, 2007).

Esses dados indicam que não basta fundamentar a necessidade de se atender às demandas de saúde das diferentes orientações sexuais que não sejam de caráter heterossexual. É preciso que se desconstruam a eternização e a des-historicização da subordinação das mulheres nos mais diversos grupos societários, bem como na perspectiva da exclusão das lésbicas e de mulheres bissexuais, combatendo as invisibilidades institucionais que as acometem e as vulnerabilizam.

A partir dessa perspectiva, tem-se como objetivo analisar modelos que podem explicar não somente a exclusão da lesbiandade e da bissexualidade de mulheres nas discussões acerca da saúde integral da mulher, mas também os efeitos da exclusão nessa área.

\section{Marco teórico-conceitual do estudo}

$\mathrm{O}$ estudo teve como marcos teórico-conceituais o habitus e o campo. Com base em Bourdieu (1992, 1998, 2001 e 2002) e Vasconcelos (2002), concebese o primeiro como um conhecimento adquirido, um "haver", indicando uma 
disposição incorporada. Tal conhecimento, construído social e historicamente, possibilita aos agentes pensar, ver e agir frente às mais variadas situações. Diferentemente da palavra hábito, que se associa a algo cristalizado, o habitus envolve uma capacidade criadora, ativa e inventiva.

Compreende-se esse conceito como uma gramática gerativa de práticas que, de um lado, fazem com que os agentes sociais reproduzam regularidades de comportamentos, e, de outro, sejam capazes de improvisar. Em outras palavras, esses agentes, através do habitus, não só reproduzem como também produzem ações. Nesse sentido, não se é apenas um ser que obedece cegamente as regras, mas que é capaz de lidar com as situaçōes imprevisíveis, criando novas modalidades práticas. Articulando as dimensões objetiva (estrutura) e subjetiva (percepção, classificação, avaliação), o habitus não só interioriza o exterior, como exterioriza o interior. Assim, ele é, ao mesmo tempo, estruturado a partir de condições determinadas, anteriores a ele, e estrutura novas condições para que se possa lidar com situações percebidas como desajustadoras (PINTO, 2000).

No que se refere a campo, com base em Bourdieu (1999, 2004), entendese este como algo construído socialmente, por meio das relações dos agentes e entre/em grupos societários que se localizam em campos sociais, inscritos numa topologia social. Como observa Bonnewitz (2003), esse conceito se contrapõe ao tradicional conceito piramidal e hierárquico de sociedade, enfatizando a dimensão relacional das posições sociais, ocupadas pelos agentes sociais a partir do capital que acumulam econômica, cultural, social e simbolicamente.

Com o conceito de Bourdieu de campo, podemos ter uma visão espacial tanto dos agentes como dos grupos sociais dos quais eles fazem parte. Assim, é possível fazer um mapeamento de como os se distribuem nos espaços sociais, que podem ser autônomos ou não, levando-nos a enxergar não só onde se localizam, mas as lutas que ocorrem entre eles.

Esse autor, entendendo o campo como um espaço de forças opostas, compara-o a um jogo cujos agentes participam, ora aceitando as regras, ora impondo-as, ora blefando sobre elas; "assim como a força relativa das cartas muda conforme os jogos, assim também a hierarquia das diferentes espécies de capital (econômico, cultural, social, simbólico) varia nos diferentes campos" (BONNEWITZ, 2003). Assim, para Bourdieu, todo campo é, ao mesmo tempo, um campo de forças e de luta, para sua manutenção ou transformação. (BOURDIEU, 2004). 
Enquanto no conceito de habitus buscou-se desvelar os modelos que estruturam o olhar sobre a homossexualidade feminina na atenção à saúde da mulher, em campo procurou-se compreender a contextualização desses modelos. Assim, entendendo os modelos como reflexos de habitus, eles podem ser modificados a partir das sanções do campo.

\section{Método do estudo}

Em termos de método, foi empregado o desenho de ensaio, entendendo tal modalidade como um exercício crítico de procura, de caráter exploratório, acerca de um tema ou objeto de meditação, buscando uma nova forma de olhar o assunto (TOBAR \& YALOUR, 2001). Seguindo esse desenho metodológico, e a experiência dos autores como profissionais de saúde, o estudo baseou-se em dois conjuntos de fontes.

$\mathrm{O}$ primeiro diz respeito à produção cientifica do conhecimento acerca do assunto, traduzido na publicação de artigos em periódicos na área da saúde. Para o acesso a esse acervo, foram utilizadas as bases de dados Lilacs (Literatura Latino-Americana e do Caribe em Ciências da Saúde) e Medline (Medical Literature Analysis and Retrieval System Online), bem como a biblioteca virtual SciELO (Scientific Electronic Library Online), por meio do portal da Biblioteca Virtual de Saúde (BVS).

Nesse portal, foram localizados 07 artigos nacionais voltados para o tema, homossexualidade feminina no Brasil, na área da saúde e 01 a partir da referência de uma das autoras desses artigos, encontrado fora do portal de pesquisas, constituindo-se assim 08 artigos como fontes da pesquisa

$\mathrm{O}$ segundo conjunto de fontes se refere a documentos que - direta ou indiretamente - asseguram o atendimento às demandas de saúde de mulheres que se assumam lésbicas ou bissexuais femininas ou que vivenciam relações homoafetivas e/ou homoeróticas. A partir desses critérios, foram consultados os seguintes documentos: Política de Atenção Integral à Saúde da Mulher-Princípios e Diretrizes (BRASIL, 2004b); II Plano Nacional de Políticas para Mulheres (BRASIL, 2008c); Política Nacional de Saúde Integral de Lésbicas, Gays, Bissexuais, Travestis e Transexuais-LGBTT (BRASIL, 2008a; 2008b); Dossiê Saúde das Mulheres Lésbicas: Promoção da Equidade e da Integralidade (Rede Feminista de Saúde, 2006); e códigos de ética de sete categorias profissionais da 
área da saúde, escolhidas aleatoriamente - Serviço Social, Psicologia, Medicina,

Fisioterapia, Fonoaudiologia, Enfermagem e Nutrição.

Os artigos publicados nos periódicos científicos receberam o tratamento de análise de conteúdo, modalidade temática (BARDIN, 1979; MINAYO, 2006). Com base nesse desenho de análise, foram percorridas as seguintes etapas: (a) leituras exaustivas dos artigos; (b) identificação dos núcleos de sentido dos conteúdos dos artigos; (c) elaboração de temáticas que serviram de eixos da discussão sobre o assunto. Com base nas temáticas que sintetizavam os artigos, foi estabelecido um diálogo entre os documentos do segundo conjunto de fontes, levando-se em conta o marco-conceitual teórico do estudo.

\section{Caracterização das fontes}

No que se refere aos artigos publicados em periódicos científicos, identificados na BVS sobre homossexualidade feminina e saúde, observa-se o pouco investimento dedicado à investigação do assunto. As publicações relacionadas a ele, além de escassas, são relativamente recentes (quadro I).

\section{Quadro I: Caracterização dos Artigos Estudados}

\begin{tabular}{|l|l|l|l|}
\hline Autoria & Ano & \multicolumn{1}{|c|}{ Foco da publicação } & \multicolumn{1}{c|}{ Método } \\
\hline Coelho & 2001 & $\begin{array}{l}\text { Tratamento dispensado às mulheres que relatam } \\
\text { sua orientação sexual diferente da heterossexual a } \\
\text { ginecologistas }\end{array}$ & $\begin{array}{l}\text { Pesquisa Quantitativa } \\
\text { descritiva. }\end{array}$ \\
\hline $\begin{array}{l}\text { Facchini } \\
\text { \& Barbosa }\end{array}$ & 2006 & $\begin{array}{l}\text { As trilhas percorridas por mulheres lésbicas em } \\
\text { busca de atenção a sua saúde, em diversos países. }\end{array}$ & $\begin{array}{l}\text { Dossiê com reflexões e } \\
\text { análises quantitativas }\end{array}$ \\
\hline $\begin{array}{l}\text { Barbosa \& } \\
\text { Koyama }\end{array}$ & 2006 & $\begin{array}{l}\text { Descrição da proporção de mulheres que fazem sexo } \\
\text { com mulheres, com base em três recortes temporais. }\end{array}$ & Inquérito populacional \\
\hline Almeida & 2009 & $\begin{array}{l}\text { Compreensão do processo de transformação do } \\
\text { "corpo lésbico" dos primeiros tempos da epidemia } \\
\text { da AIDS até os dias atuais }\end{array}$ & $\begin{array}{l}\text { Pesquisa Qualitativa } \\
\text { com observação } \\
\text { participante, entrevistas } \\
\text { e análise documental }\end{array}$ \\
\hline $\begin{array}{l}\text { Barbosa \& } \\
\text { Facchini }\end{array}$ & 2009 & $\begin{array}{l}\text { Adoção de cuidados à saúde entre mulheres que } \\
\text { fazem sexo com mulheres e as representações } \\
\text { relativas a gênero, sexualidade e ao corpo. }\end{array}$ & $\begin{array}{l}\text { Pesquisa qualitativa, } \\
\text { com observação } \\
\text { etnográfica e entrevistas }\end{array}$ \\
\hline Lionço & 2008 & $\begin{array}{l}\text { Pertinência de uma política de saúde para a população } \\
\text { de gays, lésbicas, bissexuais, travestis e transexuais. }\end{array}$ & Ensaio teórico \\
\hline Paiva et al & 2008 & $\begin{array}{l}\text { Opiniões e atitudes sobre sexualidade da população } \\
\text { urbana brasileira }\end{array}$ & Inquérito populacional \\
\hline
\end{tabular}



temáticas oriundas da análise dos artigos, oito foram levados em conta (Quadro II).

\section{Quadiro II: Caracterização dos Documentos}

\begin{tabular}{|c|c|}
\hline Título do documento & Destaque \\
\hline $\begin{array}{l}\text { Programa Nacional De Direitos } \\
\text { Humanos. Brasília (BRASIL, 2001). }\end{array}$ & $\begin{array}{l}\text { Recomendação para que se buscasse por meio de planos e } \\
\text { programas, o enfrentamento e combate à homofobia no país. }\end{array}$ \\
\hline $\begin{array}{l}\text { Política de Atenção Integral à Saúde } \\
\text { da Mulher - Princípios e Diretrizes } \\
\text { (Ministério da Saúde, 2004) }\end{array}$ & $\begin{array}{l}\text { "atingir as mulheres em todos os ciclos de vida... (mulheres } \\
\text { negras, indígenas, residentes em áreas urbanas e rurais, } \\
\text { residentes em locais de difícil acesso, em situação de risco, } \\
\text { presidiárias, de orientação homossexual, com deficiência, } \\
\text { dentre outras)" (p. 63). }\end{array}$ \\
\hline $\begin{array}{l}\text { Brasil Sem Homofobia: Programa } \\
\text { de combate à violência e à } \\
\text { discriminação contra GLTB e } \\
\text { promoção da cidadania homossexual } \\
\text { (BRASIL, 2004a). }\end{array}$ & $\begin{array}{l}\text { Princípios para a formulação de políticas e programas } \\
\text { específicos visando à melhoria da situação de vida dos } \\
\text { grupos GLBT. }\end{array}$ \\
\hline $\begin{array}{l}\text { Resolução CFP No 012/2005/ Código } \\
\text { de Ética do Psicólogo (CFP, 2005) }\end{array}$ & $\begin{array}{l}\text { Veda ao psicólogo, quando do exercício de suas funções } \\
\text { profissionais, induzir a convicções políticas, filosóficas, } \\
\text { morais, ideológicas, religiosas, de orientação sexual ou a } \\
\text { qualquer tipo de preconceito (Artigo } 2^{\circ} \text { ). }\end{array}$ \\
\hline $\begin{array}{l}\text { Resolução CFESS N 489/2006 } \\
\text { de } 03 \text { de junho de } 2006 / \text { Código } \\
\text { de Ética de Assistentes Sociais } \\
\text { (CFESS, 2006) }\end{array}$ & $\begin{array}{l}\text { "Estabelece normas vedando condutas discriminatórias } \\
\text { ou preconceituosas, por orientação e expressão sexual } \\
\text { por pessoas do mesmo sexo, no exercício profissional do } \\
\text { assistente social, regulamentando princípio inscrito no } \\
\text { Código de Ética Profissional". }\end{array}$ \\
\hline $\begin{array}{l}\text { II Plano Nacional de Políticas } \\
\text { para Mulheres/Governo Federal } \\
\text { (Brasil, 2008c) }\end{array}$ & $\begin{array}{l}\text { Proposta da construção de uma cultura igualitária, } \\
\text { democrática e não reprodutora de estereótipos de gênero, } \\
\text { raça/etnia, orientação sexual e geração, bem como o } \\
\text { enfrentamento do racismo, sexismo e lesbofobia. }\end{array}$ \\
\hline $\begin{array}{l}\text { Política Nacional de Saúde Integral } \\
\text { de Lésbicas, Gays, Bissexuais, } \\
\text { Travestis e Transexuais - LGBTT } \\
\text { (BRASIL, 2008a, 2008b) }\end{array}$ & $\begin{array}{l}\text { Reconhecimento de "que a orientação sexual e identidade } \\
\text { de gênero constituem situaçôes muito mais complexas e são } \\
\text { fatores de vulnerabilidade para a saúde..." (p. 3). }\end{array}$ \\
\hline $\begin{array}{l}\text { Resolução CFM No1931/2009/ } \\
\text { Código de Ética Médica (CFM, 2009) }\end{array}$ & $\begin{array}{l}\text { Direito do médico não ser discriminado por diversas } \\
\text { questōes, dentre ela a orientação sexual }\end{array}$ \\
\hline
\end{tabular}




\section{A Invisibilidade da homossexualidade feminina na área da saúde}

A partir dos dois conjuntos de fontes, pode-se visualizar a invisibilidade da homossexualidade feminina na área da saúde como sendo atravessada por dois campos: o das políticas (traduzidos pelos documentos legais) e o científico (aqui representado pela produção de artigos).

No campo das políticas, não se pode falar de uma invisibilidade da temática em questão. Ao contrário, ao focalizarem os direitos das diversas orientações sexuais e a tradução desses direitos na assistência à saúde, os documentos trazem uma visibilidade ao tema em questão. Entre esses documentos, destaca-se o "Programa Nacional De Direitos Humanos" (BRASIL, 2001) que - direta ou indiretamente - serve de base para que outros documentos legais abram espaço para a discussão das orientações sexuais não hegemônicas. Especificamente na área da saúde, esse programa traduz-se na "Política Nacional de Saúde Integral de Lésbicas, Gays, Bissexuais, Travestis e Transexuais - LGBTT” (BRASIL, 2008a; 2008b).

Se de um lado, os discursos do campo político procuram trazer para o campo dos direitos a homossexualidade feminina em específico e a homossexualidade em geral, de outro, a produção científica aponta certa invisibilidade dessa temática no interior das práticas de saúde. Gomes (2009) observa que os discursos não correspondem ao fato de se aceitar uma pessoa, independentemente de sua orientação sexual. Nesse sentido, poderíamos considerar que a flexibilização dos discursos não corresponde - necessariamente - à flexibilização das práticas.

Por conta da invisibilidade a que as mulheres são levadas - podendo ela ocorrer desde a adolescência, nas escolas - os autores dos artigos apontam para as seguintes implicações: alto grau de estresse; desconforto por causa do não acolhimento das especificidades de suas demandas de saúde e baixa efetividade em tratamentos.

Almeida ${ }^{1}$ (2009), dentre suas conclusões, destaca que a falta de ambiente propício à especificidade lésbica na assistência pode fazer com que o atendimento seja camuflado e as informaçôes sejam negligenciadas bilateralmente, uma vez que as usuárias do serviço não se sentiam à vontade para declarar sua sexualidade e falarem sobre suas vivências. Isso tanto pode acirrar as vulnerabilidades, inclusive no quesito saúde mental, como fazer com que os profissionais de saúde não prestem a essas usuárias uma assistência qualificada. 
$\mathrm{Na}$ pesquisa de Coelho (2001) com mulheres lésbicas e bissexuais ${ }^{2}$, foram detectadas as queixas das mulheres acerca do preconceito e da indiferença, uma vez relatada a não heterossexualidade. Observou-se também o receio de maus-tratos quando relatada a orientação sexual. Dessa forma, as consultas ginecológicas podiam negligenciar ou ignorar doenças ou informações relevantes para a vida sexual saudável da mulher lésbica ou bissexual.

Lionço (2008) refere que a orientação sexual e a identidade de gênero, mais do que demandas para políticas públicas específicas, devem ser consideradas como determinantes associados à saúde. Salienta, ainda, que os profissionais de saúde devem ter em seus currículos conteúdos a respeito do enfrentamento do preconceito relacionado à orientação sexual e à identidade de gênero, a fim de que não caiam em naturalizações ou preconceitos.

As discussões acerca da invisibilidade da homossexualidade feminina na área da saúde - implícita ou explicitamente - apontam modelos que estruturam a atuação dos profissionais de saúde ao lidarem com lésbicas e mulheres bissexuais. Os textos focalizam - direta ou indiretamente - a crítica a tais modelos.

A crítica aos modelos que explicam a invisibilidade da homossexualidade/ lesbiandade na área da saúde, de certa forma, reflete uma perspectiva do movimento social relacionada a lésbicas e mulheres bissexuais, ou vinculada à defesa dos direitos da população LGBT em geral. Nesse sentido, tanto no conjunto dos artigos estudados, quanto nos documentos legais consultados, notase a influência de forças do campo do movimento social para que haja mudanças de certos habitus que fazem com que se exclua do foco da atenção integral à saúde as demandas das lésbicas e de mulheres bissexuais.

A explicitação dos modelos que estruturam essa exclusão intenciona tornar visível o que foi excluído. Bourdieu (1999), ao tratar do movimento de gays e lésbicas, considera que essa subversão visa à destruição e à construção simbólicas, no sentido de se imporem novas categorias de percepção e de avaliação para construir um grupo ou destruir a divisão entre grupo estigmatizante e grupo estigmatizado.

Um dos modelos que podem explicar a exclusão aqui abordada é o da heteronormatividade. Esse modelo - que estrutura habitus que veem e pensam a sexualidade como única e exclusivamente de ordem heterossexual - pode fazer com que, de um lado, haja um despreparo em se lidar com a pluralidade da orientação sexual e, de outro, produzam-se dificuldades de as mulheres 
revelarem sua sexualidade não heterossexual a esses profissionais (BARBOSA;

FACCHINI, 2009). Caminhando na contramão desses habitus, na literatura estudada, propõe-se uma desnaturalização da heterossexualidade, considerandose outras sexualidades legítimas (LIONÇO, 2008).

Bourdieu (1999) compreende a ordem heteronormativa como uma ficção coletiva que se construiu, em parte, para se opor à homossexualidade. A dominação exercida por parte dessa ordem é implícita ou explicitamente combatida pelos textos estudados. Entretanto, não se pode desconsiderar que esse combate ainda opera no eixo da contra-hegemonia. $\mathrm{O}$ fato de a produção dos artigos científicos serem tão escassos no campo da saúde pode ser visto como um dos indicadores da desconsideração ou desqualificação da homossexualidade feminina como temática. Por outro lado, junto a esse conjunto de forças que visam à manutenção da heteronormatividade, há lutas que operam em oposição a esse habitus. Essa luta obtém o seu reconhecimento máximo quando passa ser objeto do campo das políticas, traduzidas no Programa Federal Brasil sem Homofobia (BRASIL, 2004a) e na Política Nacional de Saúde Integral de LGBTT (Ministério da Saúde, 2008). Outro modelo que pode explicar a invisibilidade aqui abordada é o biomédico. Esse modelo - constituído pela abordagem da anátomo-fisiopatologia - produz habitus que estruturam olhares profissionais generalizantes (incapazes de perceber as diferenças) e etnocêntricos (constituído por uma tradição cartesiana que atravessa séculos) (ALMEIDA, 2009). Esses olhares não só revelam um despreparo para se lidar com as especificidades sexuais, mas também não permitem que mulheres revelem sua lesbiandade ou sua bissexualidade (ALMEIDA, 2009; BARBOSA \& FACCHINI, 2009). Junto a isso, ao longo do tempo, esse modelo estruturou um discurso médico que contribuiu para a patologização das sexualidades socialmente estigmatizadas (LIONÇO, 2008).

Apesar, de no campo da biomedicina, ter se estruturado um discurso hegemônico que, além de não visualizar, não realiza uma escuta da homossexualidade feminina, outros habitus vêm sendo desenvolvidos para tornar visível o que está invisível. Isso se tornou possível pela aliança estabelecida pelos campos das políticas e dos movimentos sociais, que, de certa forma, se engajaram na luta por mudanças das forças conservadoras presentes no campo da biomedicina.

Outro desdobramento diz respeito à luta pela inclusão de agentes vistas como "mulheres que fazem sexo com mulheres" na atenção à saúde e na prevenção 
de doenças. Isso se observou principalmente nas açōes voltadas para as doenças sexualmente transmissíveis (DST) em geral e para a AIDS em específico. Nesse sentido, ao se tornar visível a vulnerabilidade dessas mulheres frente a essas doenças, surgiu a "necessidade de oferecer maior visibilidade politica às lésbicas" (ALMEIDA, 2009, p. 310). Esse jogo de mudanças de forças, entretanto, ainda não ocorreu na totalidade do campo da saúde. Em alguns setores desse campo, por serem vistas como "não mulheres", lésbicas ainda "são excluidas do acesso a exames papanicolan e de mama, que são parte do protocolo de exames comuns às mulheres" (Almeida, 2009, p.313). Nesse cenário, a consulta ginecológica pode ser vista como espaço problemático, porque nele não só se expõe o corpo em si, como comportamentos socialmente desvalorizados podem ser revelados (BARBOSA; FACCHINI, 2009).

A invisibilidade de lésbicas e mulheres bissexuais ultrapassa a área da saúde. Isso ocorre mesmo nos eventos que trazem a luta contra a discriminação da população LGBT. Nas Paradas do Orgulho GLBT do Rio de Janeiro de 2003 e 2004, por exemplo, a presença dessas mulheres foi menor do que a dos gays, 20,2\% contra 42,1\% (REDE..., 2006).

Um exemplo emblemático de tornar mais visível a homossexualidade feminina no campo da saúde é a Política Nacional de Saúde Integral de Lésbicas, Gays, Bissexuais, Travestis e Transexuais - LGBTT (Ministério da Saúde, 2008). Ainda que tal política não tenha fluído totalmente na corrente sanguínea do campo da biomedicina, não se pode negar, de um lado, a possibilidade de forças de campos distintos se unirem para promover a inclusão de cidadãs excluídas por conta de sua orientação sexual, e, de outro, a viabilidade de se desenvolver habitus que possibilitem considerar as demandas de saúde dos agentes que não partilhem de forma exclusiva a orientação heterossexual.

\section{Da invisibilidade à violência}

Dimensionar a violência cometida contra homossexuais não é tarefa fácil. Isso se explica, em parte, pela "ausência de definição da natureza da violência contra a população de homossexuais, quando notificada, bem como na subnotificação da mesma” (LIONÇO, 2008, p. 15). Ainda que haja essa dificuldade, pode-se identificar, nas fontes estudadas, a violência como uma temática que sintetiza a discussão acerca de lésbicas e mulheres bissexuais na área da saúde. As situações de violência cometidas contra essas mulheres são recorrentemente constatadas. 
Comparadas às mulheres heterossexuais, as lésbicas expressam níveis elevados de violências físicas e psicológicas, tanto nos espaços privados quanto nos lugares públicos (Ministério da Saúde, 2008). Segundo Almeida (2009), elas ficam mais expostas à violência psicológica.

Talvez por conta dessas situaçôes, algumas "mulheres que fazem sexo com mulheres" não queiram ser vistas como lésbicas. Os temores de se tornarem alvos de atos violentos, podem levar "ao silêncio sobre as práticas e/ou desejos homoeróticos e a restrições que podem impactar negativamente as vivências amorosas" (REDE..., 2006, p. 20). Contraditoriamente, isso pode contribuir para que se mantenha a invisibilidade ou negação da existência da homossexualidade feminina. Como desdobramentos, podemos não ter uma compreensão do perfil dessas mulheres, das suas demandas e das suas dificuldades de acesso aos serviços de saúde (ALMEIDA, 2009). Assim, esse silêncio sobre a orientação sexual por parte das lésbicas pode contribuir tanto para a sua vulnerabilidade quanto para a sua invisibilidade social, trazendo dificuldades para que as políticas públicas possam melhor focalizá-las (REDE..., 2006).

Tanto o silêncio quanto o não silêncio da homossexualidade feminina podem causar violência psicológica, com efeitos de agravos à saúde, por conta de se tratar de um assunto amplamente atravessado por preconceitos e discriminações. Assim, a ocultação das práticas e desejos homossexuais e o enfrentamento social pela estratégia de 'sair do armário' podem se associar ao estresse e ao isolamento das pessoas (REDE..., 2006).

Aprofundandoa discussão sobreaviolência perpetrada contraa homossexualidade feminina, propõe-se com base, tanto nas fontes estudadas, quanto no marco teórico-conceitual, discutir o tema mais no plano simbólico do que no âmbito das violências cometidas abertamente entre pessoas. Bourdieu (2009) destaca que, ao lado da violência aberta, há aquela de ordem simbólica, que pode ser entendida como a que é eufemizada, branda, invisível ou dissimulada (oculta). Segundo esse autor, enfatizar a violência simbólica não significa minimizar o papel da violência física ou fazer esquecê-la, nem entendê-la como oposta à violência real, uma violência meramente espiritual, sem efeitos reais (BOURDIEU, 1999).

A partir dessa dimensão, pode-se entender a invisibilidade da homossexualidade feminina como uma violência simbólica. No caso dos gays e das lésbicas, Bourdieu (1999) considera que: 
a opressão como forma de 'invisibilização' traduz uma recusa à existência legítima, pública, isto é, conhecida e reconhecida, sobretudo pelo Direito, e por uma estigmatização que só aparece de forma realmente declarada quando o movimento reivindica a visibilidade (p. 143-4).

Outra forma de ver a violência simbólica contra a homossexualidade em geral se traduz em abordar esse problema à luz da hegemonia de modelos culturais de gênero. A reificação desses modelos tanto pode produzir violência contra aquelas pessoas que a eles não aderem, como podem contribuir para a invisibilidade da própria violência (GOMES, 2009). Assim, ou se anulam as transgressões por meio de ações disciplinadoras, ou se retiram as palavras a elas referentes do conjunto dos vocábulos que estruturam os discursos. Nesse sentido, a não nomeação pode - simbolicamente - revelar uma violência contra as transgressões da heteronormatividade.

Segundo Greig (2008), por meio dessa violência - identificada por nós como simbólica - vigiam-se as fronteiras entre os gêneros e entre as orientações sexuais, e se determinam as relações sexuais entre os gêneros. No campo da prestação de serviços de saúde, ainda segundo esse autor, as pessoas que conspiram contra essas fronteiras são colocadas na clandestinidade, seja pelo não atendimento de suas demandas de saúde sexual, seja pela negação das informações que, por direito, deveriam lhes ser disponibilizadas.

Frente a essa reflexão acerca da violência simbólica cometida contra a homossexualidade, pergunta-se: a homossexualidade feminina se diferenciaria da masculina? Ainda que de forma hipotética, pode-se dizer que sim. Como ponto de partida para a sustentação dessa discussão, recorre-se a Bourdieu (1999) que, ao associar a violência simbólica à dominação simbólica, aponta diferentes tipos de domínio simbólico (branco, masculino e burguês) aos quais as pessoas podem estar submetidas. Caminhando nessa lógica, pode-se considerar que as lésbicas podem estar mais sujeitas a violência simbólica do que os gays, uma vez que na constituição de seu status contabilizam-se a superposição de diferentes dominações simbólicas. Indo mais longe, poder-se-ia hipoteticamente considerar maior superposição de dominações simbólicas para as lésbicas negras e pobres.

Toda a reflexão sobre a dominação simbólica da heteronormatividade pode iluminar a discussão da não visibilidade de lésbicas e de mulheres bissexuais no campo da saúde. Os agentes desse campo, antes de serem profissionais, são partícipes de grupos sociais influenciados por modelos culturais. Assim, ao lidar 
com essas mulheres, esses agentes - consciente ou inconscientemente - tanto podem lançar mão de habitus que transformam o que não é comum no que é patológico, quanto podem utilizar habitus que excluem o que é diferente a partir da sua não-consideração.

Contrapondo-nos a esse quadro, observa-se que na área da saúde tangenciamse diferentes campos constituídos de forças e de lutas que visam à transformação das forças. Assim, se o campo das práticas de saúde ainda não conseguiu ser suficientemente inclusivo para acolher as demandas das mulheres, cuja sexualidade não se estrutura exclusivamente a partir da heteronormatividade, no campo das políticas de saúde - influenciado pelo campo dos movimentos sociais ou a eles aliado - os discursos asseguram o direito dessas mulheres de terem suas demandas de saúde atendidas. Na luta para transformar habitus que excluem lésbicas e mulheres bissexuais em habitus que as incluem na área da saúde, se faz necessário obter maior parceria com o campo científico, que pode melhor consolidar a aliança entre o campo das políticas e o dos movimentos sociais. $\mathrm{O}$ caminho a ser percorrido já foi iniciado, ainda que seja representado por uma escassa produção científica nacional.

\section{Considerações finais}

Em geral, os estudos analisados apontam para o fato de que lésbicas e mulheres bissexuais não são apoiadas, por parte dos profissionais, no campo da atenção integral à saúde da mulher, a verbalizar suas orientações sexuais quando buscam assistência. Tal situação escamoteia um atendimento seguro, produzindo exclusão e violência simbólica, apesar de programas governamentais preconizarem o contrário. Por outro lado, com base teórica em Bourdieu, observa-se que existe a possibilidade de transformação desses habitus a partir da aliança entre os agentes dos campos das políticas, da ciência e dos movimentos sociais interessados em trazer as questões da homossexualidade feminina não só para a pauta dos discursos, mas, sobretudo, para as práticas da atenção à saúde da mulher.

Esse empreendimento, tão bem assinalado nas fontes consultadas, depende de investimentos na formação dos profissionais de saúde, para que esses possam - além de terem competências técnicas para lidar com as diversidades - possam ser agentes sociais que participam na transformação de habitus sexistas e discriminatórios em boas práticas de saúde voltadas para a diversidade da sexualidade. 
As considerações - no lugar de se autodenominarem de finais - ainda são bastante iniciais, uma vez que não só constatam uma escassa produção sobre o assunto como também, de forma ensaística, se colocam no lugar de formular hipóteses a serem estudadas em futuros trabalhos, que não só levem em conta o que foi produzido, mas que também caminhem na direção de compreender o que se passa no cotidiano de lésbicas e de mulheres bissexuais e no dos profissionais de saúde que a elas prestam ou deveriam prestar assistência.

\section{Referências}

ALMEIDA, A.C. A cabeça do brasileiro. Rio de Janeiro: Record, 2007.

ALMEIDA, G. Argumentos em torno da possibilidade de infecção por DST e Aids entre mulheres que se autodefinem como lésbicas. Physis-Revista de Saúde Coletiva, v. 19, n. 2, p. 301-311, 2009.

- Da invisibilidade à vulnerabilidade: percurso do corpo lésbico na cena brasileira face à possibilidade da infecção por DST e Aids. Rio de Janeiro, 2005. $342 \mathrm{f}$. Tese (Doutorado em Saúde Coletiva) - Instituto de Medicina Social, Universidade do Estado do Rio de Janeiro, Rio de Janeiro, 2005.

BARBOSA, R.M.; FACCHINI, R. Acesso a cuidados relativos à saúde sexual entre mulheres que fazem sexo com mulheres em São Paulo, Brasil. Cadernos de Saúde Pública, sup 2, p. S291-S300, 2009.

BARBOSA, R.M.; KOYAMA, M.A. H. Mulheres que fazem sexo com mulheres: algumas estimativas para o Brasil. Cadernos de Saúde Pública, v. 22, n. 7, p. 1511-1514, 2006.

BARDIN, L. Análise de conteúdo. Lisboa: Edições 70, 1979.

BONNEWITZ, P. Primeiras liçôes sobre sociologia de P. Bourdieu. Petrópolis: Vozes, 2003.

BOURDIEU, P. Sociologia. São Paulo: Ática, 1983 (Grandes Cientistas Sociais, 39).

_. A economia das trocas simbólicas. São Paulo: Perspectiva, 1992.

.. A dominação masculina. Rio de Janeiro: Bertrand Brasil, 1999.

. O poder simbólico. Rio de Janeiro: Bertrand Russel, 1998.

. Meditaçōes pascalianas. Rio de Janeiro: Bertrand Brasil, 2001.

.. Esboço de uma teoria da prática. Oiras [Portugal]: Celta, 2002.

. Os usos sociais da ciência: por uma sociologia científica do campo científico. São Paulo: UNESP, 2004.

. O senso prático. Petrópolis: Vozes, 2009. 
BRASIL. Ministério da Saúde. Brasil Sem Homofobia: Programa de combate à violência e à discriminação contra GLTB e promoção da cidadania homossexual. Brasília: Ministério da Saúde, 2004a. Disponível em http://www.prsp.mpf.gov.br/prdc/area-de-atuacao/ dsexuaisreprod/Brasil\%20sem\%20Homofobia.pdf. Acesso em: 29 abr 2009.]

BRASIL. Ministério da Justiça. Programa Nacional De Direitos Humanos. Brasília: Ministério da Justiça/Secretaria de Estado dos Direitos Humanos, 2001. Disponível em: http://www. acaoeducativa.org.br/portal/images/stories//pndh.pdf. Acesso em: 01 maio 2010.

BRASIL. Ministério da Saúde. Política nacional de atenção integral à saúde da mulher: princípios e diretrizes / Ministério da Saúde, Secretaria de Atenção à Saúde, Departamento de Ações Programáticas Estratégicas. Brasília: Ministério da Saúde, 2004b. Disponível em: http:// conselho.saude.gov.br/ultimas_noticias/2007/politica_mulher.pdf. Acesso em: 01 maio 2010. BRASIL. Ministério da Saúde. Saúde da população de gays, lésbicas, bissexuais, travestis e transexuais. Brasília: Departamento de Apoio à Gestão Participativa / Secretaria de Gestão Estratégica e Participativa/Ministério da Saúde, 2008a. Disponível em: http://portal.saude. gov.br/portal/arquivos/pdf/texto_da_politica_lgbt_sgep.pdf. Acesso em: 01 maio 2010.

BRASIL. Ministério da Saúde. Saúde de gays, lésbicas, bissexuais, travestis e transexuais. Revista de Saúde Pública, v. 42, n. 3, p. 570-573, 2008b.

BRASIL. Presidência da República. Secretaria Especial de Políticas para as Mulheres. II Plano Nacional de Políticas para as Mulheres, 2008c. Disponível em: http://200.130.7.5/ spmu/docs/Livreto_Mulher.pdf. Acesso em: 29 abr 2009.

COELHO,L. A representação social da homossexualidade feminina nos ginecologistas do ponto de vista das mulheres lésbicas e bissexuais. Revista Tesseract, n. 4, maio 2001. Disponível em: http://tesseract.sites.uol.com.br. Acesso em: 12 abr 2010.

CONSELHO FEDERAL DE MEDICINA. Resolução CFM No 1931/2009. Disponível em: http://www.portalmedico.org.br/novocodigo/integra.asp. Acesso em: 01 maio 2010.

CONSELHO FEDERAL DE PSICOLOGIA. Resolução CFP No 012/2005. Código de Ética do Psicólogo. Disponível em: http://www.cfp.org.br/selo/Resolucao_012-05.php. Acesso em: 01 maio 2010.

CONSELHO FEDERAL DE SERVIÇO SOCIAL. Resolução $N^{\circ}$ 489/2006, de 03 de junho de 2006. Disponível em: http://www.cfess.org.br/arquivos/resolucao_489_06.pdf. Acesso em: 01 maio 2010.

FACCHINI, R.; BARBOSA R. Saúde e promoção da equidade e da integralidade das mulheres lésbicas. Brasília: Rede Feminista de Saúde, 2003.

FLEURY, A.R.D.; TORRES, A.R.R. Análise psicossocial do preconceito contra homossexuais. Estudos de Psicologia, v. 24, n. 4, p. 475-486, 2007. 
GOMES, R. Modelos culturais de gênero e violência: uma discussão para o campo da saúde. In: MENEGUEL, S.N. (Org.). Rotas Criticas II - Ferramentas para trabalhar com a violência de gênero. Santa Cruz do Sul: Edunisc, 2009, v. 1, p. 172-188.

GREIG, A. Sexo e os direitos do homem. In: CORNWALL, A.; JOLLY, S. (Orgs.). Questões de sexualidade: ensaios transculturais. Rio de Janeiro: ABIA, 2008. p. 167-174.

LIONÇO, T. Que direitos à saúde para a população GLBT? Considerando direitos humanos, sexuais e reprodutivos em busca da integralidade e da equidade. Saúde e Sociedade, v. 17, n. 2, p. 11-21, 2008.

MINAYO, M.C. de S. O desafio do conhecimento: pesquisa qualitativa em saúde. São Paulo: Hucitec 2006.

PAIVA, V.; ARANHA, F.; BASTOS, F. I. Opiniōes e atitudes em relação à sexualidade: pesquisa de âmbito nacional, Brasil 2005. Revista de Saúde Pública, v. 42, supl 1, p. 5464, 2008.

PINTO, L. Pierre Bourdieu e a teoria do mundo social. Rio de Janeiro: FGV, 2000.

REDE FEMINISTA DE SAÚDE. Saúde da Mulher Lésbica. Dossiê: promoção da equidade e da integralidade, 1996. Disponível em: http://www.redesaude.org.br/Homepage/ Dossi\%EAs/Dossi\%EA\%20Sa\%FAde\%20das\%20Mulheres\%20L\%E9sbicas.pdf. Acesso em: 29 abr 2009.

TOBAR, F.; YALOUR, M. R. Como fazer teses em saúde pública: conselhos e idéias para formular projetos e redigir teses e informes de pesquisas. Rio de Janeiro: Fiocruz, 2002.

SETTON, M.G.J., A teoria do habitus em Pierre Bourdieu: uma leitura contemporânea. Revista Brasileira de Educação, n. 20, p. 60-70, 2002.

\section{Notas}

${ }^{1}$ Almeida, com base em sua dissertação para o doutorado em 2005, elaborou o artigo Argumentos em torno da possibilidade de infecção por DST e Aids entre mulheres que se autodefinem como lésbicas, em 2009.

${ }^{2}$ Aqui são consideradas lésbicas ou bissexuais, mulheres que sentem atração sexual exclusivamente por outras mulheres e aquelas que sentem atração pelos dois sexos, respectivamente. 


\section{Abstract}

Female homosexuality in health: from invisibility to violence

This paper aims to analyze the models that may explain the invisibility of lesbian and bisexual women in the area of women's whole health care assistance. Discussing homosexuality in general, a contribution is made to deconstruct naturalist views which destitute people from their role of agents of their own sexuality, preventing them of exercising their right to live different sexual orientations other than those hetero-normative. For the theoretical reference, Pierre Bourdieu's concept of habitus and field was used. Papers published on the subject in the health care field accessed through the site of the Virtual Health Library (BVS) and government documents that provide health care programs and services to women who admit publicly to be lesbian or bisexual or for those who are experiencing homo-affective and/or homoerotic relations. It was then concluded that lesbian and bisexual women do not have any kind of support from health care professionals, in the whole health care field for women, helping them verbalize their sexual orientation, when they seek assistance.

Key words: female homosexuality; invisibility and violence; health field in Brazil. 